\title{
Shoulder scaption is dependent on the behavior of the different partitions of the infraspinatus muscle
}

\author{
Kyosuke Hoshikawa $^{1} \cdot$ Takuma Yuri $^{2,3}$ (1) Hugo Giambini ${ }^{3} \cdot$ Yoshiro Kiyoshige $^{1,2}$
}

Received: 5 November 2020 / Accepted: 30 December 2020 / Published online: 19 January 2021

(c) The Author(s) 2021

\begin{abstract}
Purpose The purpose of this study was to investigate if the three partitions (superior, middle, and inferior partitions) of the infraspinatus muscle previously described in anatomical studies will present different behavior during scapular plane abduction (scaption) as described using shear-wave elastography, especially during initial range of motion.

Methods Eight volunteers held their arm against gravity $15^{\circ}$ intervals from $30^{\circ}$ to $150^{\circ}$ in scaption. Shear-wave elastography was implemented at each position to measure shear modulus at rest and during muscle contraction, as a surrogate for muscle stiffness, of each partition. Muscle activity was defined as the difference in stiffness values between the resting positions and those during muscle contraction ( $\Delta E=$ stiffness at contraction-stiffness at rest).

Results The activity value for the middle partition was $25.1 \pm 10.8 \mathrm{kPa}$ at $30^{\circ}$ and increased up to $105^{\circ}(52.2 \pm 10.8 \mathrm{kPa})$, with a subsequent decrease at larger angle positions $(p<.001)$. The superior partition showed a flatter and constant behavior with smaller activity values except at higher angles $(p<.001)$. Peak activity values for the superior partition were observed at $135^{\circ}$ $(23.0 \pm 12.0 \mathrm{kPa})$. Increase activity for inferior partition began at $60^{\circ}$ and showed a peak at $135^{\circ}(p<.001 ; 32.9 \pm 13.8 \mathrm{kPa})$. Conclusion Stiffness measured using shear-wave elastography in each partition of the infraspinatus muscle demonstrated different behavior between these partitions during scaption. The middle partition generated force throughout scaption, while the superior and inferior partitions exerted force at end range.
\end{abstract}

Keywords Infraspinatus muscle $\cdot$ Partition $\cdot$ Rotator cuff $\cdot$ Function $\cdot$ Shear-wave elastography

\section{Introduction}

In the classic literature, the infraspinatus (ISP) muscle, one of the rotator cuff muscles, is defined as a thick triangular muscle occupying the ISP fossa [9]. The main function of the ISP muscle is to externally rotate the humerus [20] and generate a joint compression force in the gleno-humeral joint [30]. However, some investigators, using electromyogram (EMG), found that the ISP muscle acted as an abductor $[19,28]$. In shoulder abduction motion, the rotator cuff muscles compress the humeral head to the glenoid

Takuma Yuri

d2167013@yachts.ac.jp

1 Department of Physical Therapy, Yamagata Prefectural University of Health Sciences, Yamagata, Japan

2 Graduate School of Health Sciences, Yamagata Prefectural University of Health Sciences, Yamagata, Japan

3 Department of Biomedical Engineering, The University of Texas at San Antonio, San Antonio, TX, USA against the superior migration action of the deltoid muscle. The activation timing of the supraspinatus muscle has been reported to be at $45^{\circ}$ of abduction while that of the deltoid muscle at $60^{\circ}$ [19]. If the ISP muscle effectively contributed to shoulder abduction, the ISP muscle should exert enough activation at initial range, prior to that of the deltoid muscle. Recent detailed anatomical studies demonstrated that the ISP muscle was anatomically divided into two or three distinct neuromuscular partitions based on differences in their attachment sites, muscle fiber directions, and intramuscular innervations [3, 6, 15, 22, 31]. Several authors demonstrated that the anterior-most region of the humeral insertion of the ISP muscle almost reached the anterior margin of the highest impression of the greater tuberosity [22-25, 31]. In addition, Kato et al. found that one of the partitions of the ISP muscle was innervated by branches arising from the supraspinatus muscle [15]. These findings from anatomical studies suggest that the partitions of the ISP muscle may independently play an important role in shoulder abduction. 
While some investigators tried to measure independent activations of the partitions of the ISP muscle using EMG, it is difficult to measure the activation of each partition, especially in the inferior partition, throughout various shoulder motions as the fine wires can be displaced out of the muscle during contraction $[1,2,4,14]$. Shear-wave ultrasound elastography (SWE) has been previously implemented to measure shear modulus of muscles, as a surrogate for muscle stiffness. Sasaki et al. reported a linear relationship between muscle shear modulus and tetanic muscular force produced by electrical stimulation in vivo [27]. Others have implemented SWE to measure the shear modulus of the supraspinatus muscle partitions and demonstrated differences in shear modulus among the various partitions $[8,10$, 11]. These studies suggest SWE as a non-invasive imaging technique that can measure local stiffness of the rotator cuff muscles. Kuwahara et al., using elastography, investigated the functional differences in the partitions (superior, middle, and inferior partitions) of the ISP muscle during external rotation with $70^{\circ}$ abduction [20]. They suggested that the superior partition contributes to abduction motion, the middle partition act as a prime external rotator, and the inferior partition has both functions. We hypothesized that the three partitions (superior, middle, and inferior partitions) of the ISP muscle previously described in anatomical studies $[3,6,31]$ will present different behavior during scaption as described using SWE, especially during initial range of motion. A better understanding of the behavior of the individual infraspinatus muscle partitions during scaption using ultrasound elastography could provide beneficial information on patients who can hardly elevate their arms. The purpose of this study was to investigate if the three partitions (superior, middle, and inferior partitions) of the infraspinatus muscle previously described in anatomical studies would present different behavior during scaption as described using SWE.

\section{Methods}

\section{Participants}

A power analysis was performed a priori to calculate the sample size needed for one-way analysis of variance with repeated measures [effect size $=0.4, \alpha$ error $=0.05$, power $=0.95$ ] using $\mathrm{G}^{*}$ power 3.1 software (Heinrich Heine University, Duesseldorf, Germany) [7]. Thus, eight healthy male volunteers without any restrictions in their shoulder joints were recruited to this study after approval by our Institutional Ethics Review Board (\#1609-15). Their mean age, body weight, and height were $20 \pm 1$ years old, $62 \pm 2 \mathrm{~kg}$ and $174 \pm 6 \mathrm{~cm}$, respectively. The subjects' experiences in sport were at a recreation level. Written informed consent was obtained from all participants.

\section{Muscle properties measurements}

An Aixplorer ultrasound scanner (Supersonic Imagine, Aixen-Provence, France) and a $15-4 \mathrm{MHz}$ linear array probe (SL 15-4, Vermon, France) were used to measure muscle shear modulus $(\mathrm{kPa})$, as a surrogate for stiffness, in SWE mode (shoulder preset). The stiffness of the three partitions of the ISP muscle was obtained in the non-dominant arm of normal subjects. The subjects were instructed to sit on a chair and asked to rest their arms on a hand-made semicircular protractor with shelves $15^{\circ}$ intervals from $30^{\circ}$ to $150^{\circ}$ in scapular plane abduction (scaption). At each position, the stiffness at rest was measured while the participants place their arm on the shelves. The stiffness at contraction was measured while the tester moved the hand-made semicircular protractor back from the resting positions and participants held their arms against gravity at the same position for approximately ten seconds (Fig. 1). The ultrasound probe was gently placed on the skin atop each partition (superior, middle and inferior) of the ISP muscle (Fig. 2). Briefly, to obtain the B-mode image for the superior partition, the probe was placed $1 \mathrm{~cm}$ down and parallel to the scapula spine. For the middle partition, the probe was placed mid-point of the medial border of the scapula. For the inferior partition, at first, the fascia between the inferior partition of the ISP and teres minor muscles was visualized. Then, the probe was placed on the region of teres minor muscles [3, 6, 20, 31]. SWE images were simultaneously displayed on the B-mode image as a square color image. To measure the stiffness, three random images were chosen from the continuous video recording during the measurements. Three regions of interest were placed at the center of each specific muscle partition to obtain stiffness outcomes based on the shear wave speed [29]. This process was repeated for each shoulder position. The measurements were conducted by a single sonographer (KH). Muscle activity was defined as the difference in stiffness values between the resting positions and those during muscle contraction ( $\Delta E=$ stiffness at contraction - stiffness at rest) $[20,32,33]$.

\section{Statistical analysis}

SPSS statistical software (version 24.0; SPSS, Chicago, IL, USA) was used for all the statistical analyses. Intraclass correlation coefficient $\left(\mathrm{ICC}_{1,3}\right)$ was implemented to evaluate the intra-rater reliability of three images between eight subjects based on the ICC form developed by Koo and LI (one-way random effects, absolute agreement, multiple measurements) [18]. Reliability was classified as poor (less than 0.50 ), moderate (between 0.50 and 0.75 ), good (between 


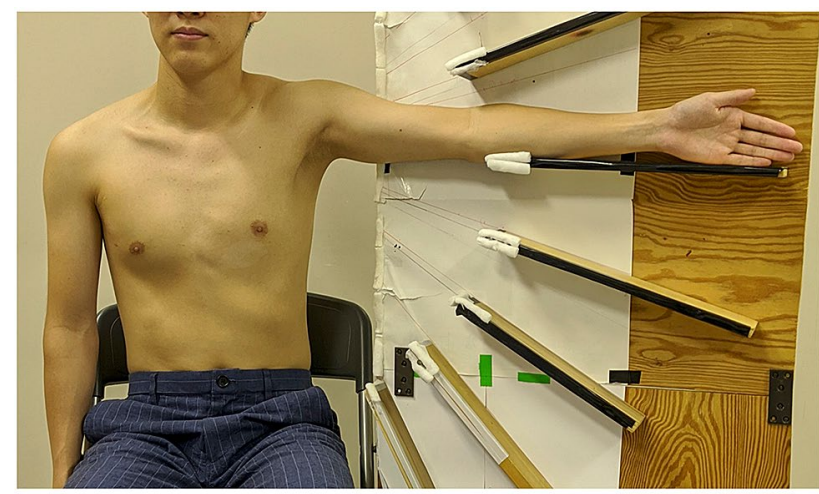

At Rest

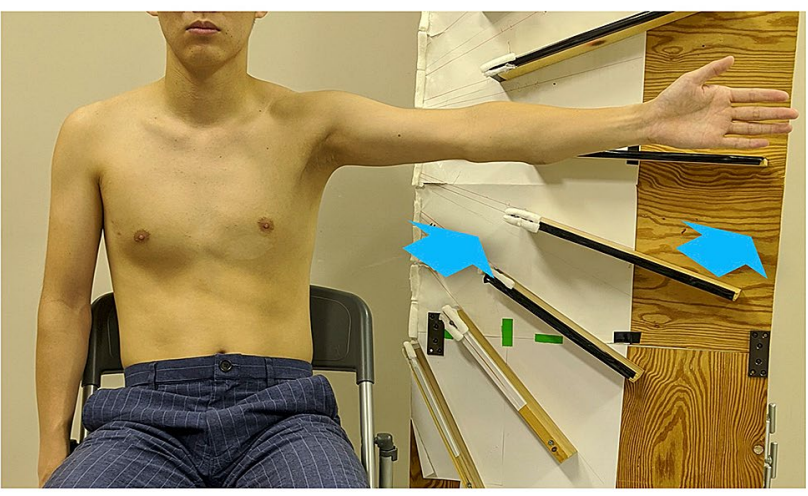

At Contraction

Fig. 1 Scaption (abduction in scapular plane). SWE measurements of the ISP muscle were obtained $15^{\circ}$ intervals from $30^{\circ}$ to $150^{\circ}$ using a hand-made semicircular protractor with shelves $15^{\circ}$ intervals in scaption. At each position, the shear modulus at rest was measured while the participants place their arm on the shelves. The shear modulus at contraction was measured, while the tester moved the handmade semicircular protractor back from the measurements at rest and participants hold their arms just against gravity at that position for approximately ten seconds

0.75 and 0.90), and excellent (greater than 0.90). Because the Shapiro-Wilk test did not indicate a normal distribution of the data, non-parametric tests were conducted. Friedman with Dunn's post hoc tests was used to evaluate differences in measurement outcomes among angles during scaption in three partitions. Statistical significance was set to $p<0.05$.

\section{Results}

ICC $_{1,3}$ analysis resulted in excellent reliability (0.994-0.999). Stiffness values at rest (mean \pm SD) in both middle and inferior partitions resulted in peak outcomes at $45^{\circ}(32.5 \pm 7.5 \mathrm{kPa}$ for middle partition and $31.4 \pm 7.7 \mathrm{kPa}$ for inferior partition), decreasing with increasing scaption angles $(p=0.005$ for middle partition and $p=0.010$ for inferior partition). Stiffness of the superior partition showed a constant increase in values with shoulder scaption positions $(p<0.001$; Fig. 3). Peak stiffness at rest of the superior partition was $32.6 \pm 9.1 \mathrm{kPa}$ at $150^{\circ}$.

Stiffness for the middle partition during muscle contraction increased up to $105^{\circ}(81.9 \pm 10.7 \mathrm{kPa})$, with a subsequent decrease $(p<0.001)$. The superior and inferior partitions showed a flatter and constant behavior compared to the middle partition, except at higher shoulder angles. Peak stiffness of the superior and inferior partitions were $55.0 \pm 10.5 \mathrm{kPa}$ at $135^{\circ}$, and $52.4 \pm 12.9 \mathrm{kPa}$ at $135^{\circ}$, respectively ( $p<0.001$ for both superior and inferior partitions; Fig. 3).

The activity value for the middle partition was $25.1 \pm 10.8 \mathrm{kPa}$ at $30^{\circ}$ and increased up to $105^{\circ}$ $(52.2 \pm 10.8 \mathrm{kPa})$, with a subsequent decrease at larger angle positions $(p<0.001)$. The superior partition showed a flatter and constant behavior with smaller activity values except at higher angles $(p<0.001)$. Peak activity values for the superior partition was observed at $135^{\circ}(23.0 \pm 12.0 \mathrm{kPa})$. Increase activity for inferior partition began at $60^{\circ}$ and showed a peak at $135^{\circ}(p<0.001$; Fig. $3 ; 32.9 \pm 13.8 \mathrm{kPa})$.

\section{Discussion}

The purpose of the current study was to investigate the behavior of the superior, middle, and inferior partitions of the ISP muscle during scaption at rest and during muscle contraction in vivo using SWE. As we hypothesized, the shear modulus, as a surrogate for stiffness, measured using SWE in each partition of the ISP muscle demonstrated different behavior during scaption. To our knowledge, this is the first study to investigate the functional behaviors in three anatomical partitions of the ISP muscle during scaption.

We obtained three quantitative outcomes in the three partitions of the ISP muscle; stiffness at rest, during muscle contraction, and the activity value representing the difference between these two. As muscle is stretched, it will tend to increase its passive resistance to deformation. Koo et al. showed a linear relationship between shear modulus measured by SWE and passive force [17]. Thus, the stiffness at rest can indicate the length of muscle. Stiffness at rest from the superior partition gradually increased in this study. This indicates that the superior partition was gradually elongated with increasing elevation angles. On the other hand, stiffness at rest for the middle and inferior partitions gradually decreased, indicating that these partitions shortened from the starting and elongated position. SWE-measured stiffness during muscle contraction is the sum of the stiffness at rest and those measured during voluntary contraction. Therefore, to estimate the stiffness generated by voluntary contraction, we defined the difference in stiffness at rest and during contraction $(\Delta E=$ stiffness during contraction - stiffness at rest) 

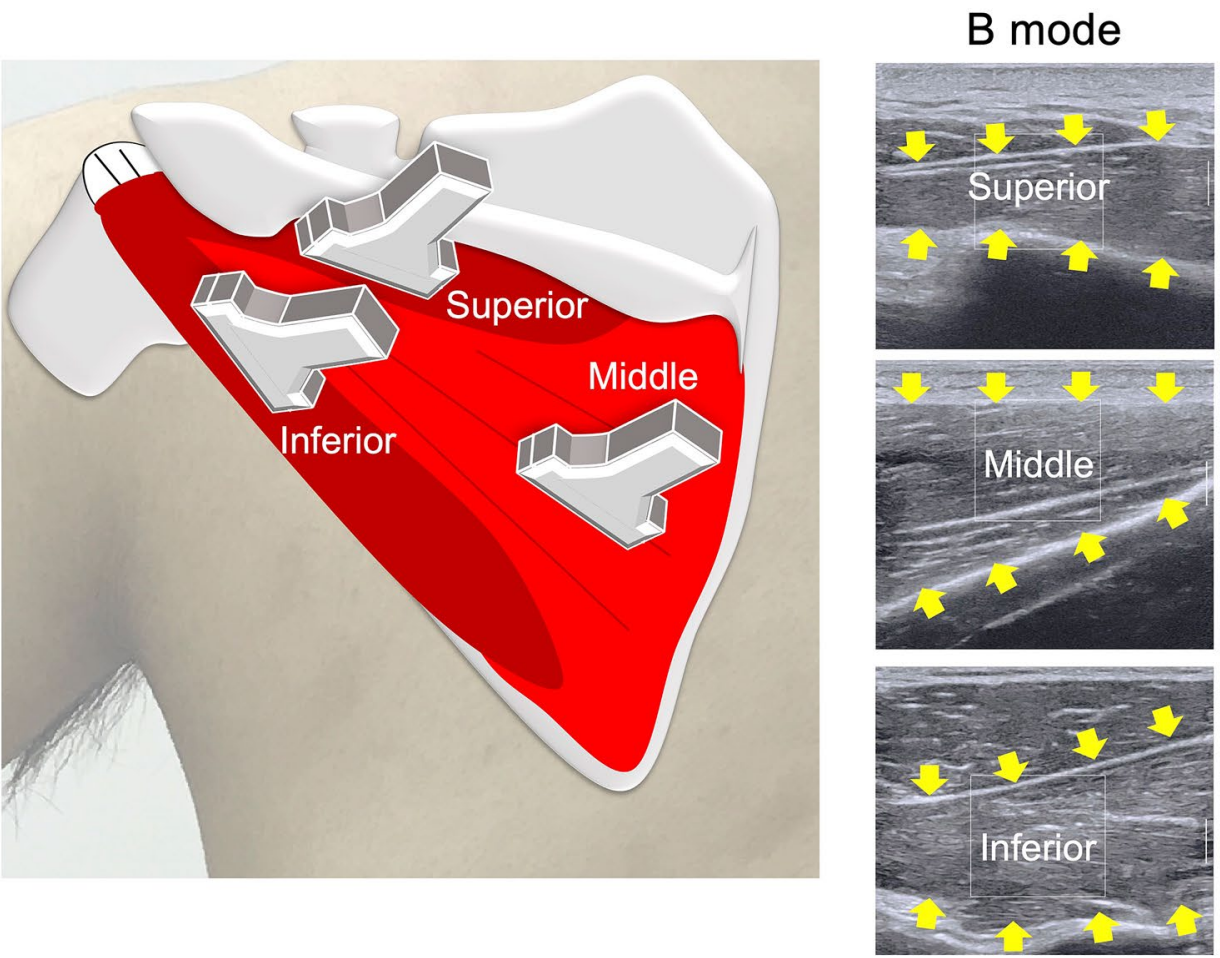

\section{SWE mode}

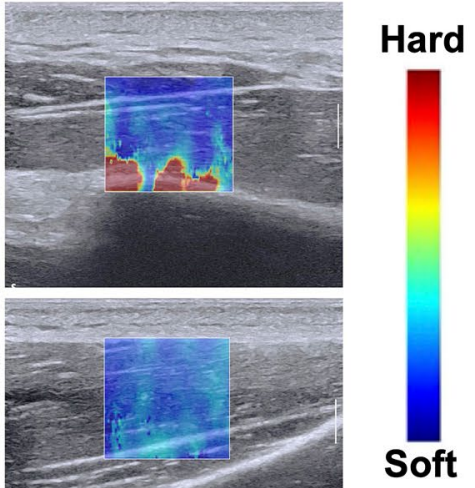

Fig. 2 Probe orientations for the superior, middle, and inferior partitions of the infraspinatus muscle. Yellow arrows indicated the border of each partition. The SWE images were displayed in color-coded map with harder tissue represented in red and softer tissue in blue as activity value. When the measured stiffness at rest results in substantial values due to its physical elongated condition, this will in turn yield low activity outcomes, with the muscle acting as a dynamic tenodesis. This indicates that the inferior partition acted as dynamic tenodesis during the initial range of motion. The activity value of inferior partition gradually increased from $60^{\circ}$ up to $135^{\circ}$. The superior partition became tight with increasing elevating angles and had small activity value with a peak outcome at $135^{\circ}$. On the contrary, the middle partition was the only partition of the three not showing low activity values from the initial range to end range, with a peak at $105^{\circ}$.

EMG studies have demonstrated that ISP muscle activation is described by a trapezoidal behavior with a peak value at late mid-range of scaption in a no-load type condition $[12,21]$. These results coincide with the activity values in the middle partition observed in our study. Some investigators measured independent activation of those partitions using EMG, and concluded that the muscle partitions have different roles [1, 2, 4, 14]. However, EMG measurements from the partitions were not obtained during scaption, rather during specific positions, e.g. empty can test. On the other hand, Alenabi et al. 2019 [2] measured EMG in the superior and middle partitions of the ISP muscle at $30^{\circ}, 90^{\circ}$, and $150^{\circ}$ during scaption and demonstrated that the activation of both the superior and middle partitions of the ISP muscle, with $50 \%$ maximal voluntarily contraction, increased with increasing angle. These results are not in line with those obtained in the current study for the middle partition. One possible explanation is the difference in the strength measurements. The authors applied 50\% maximal voluntary contraction, while in the current study we only considered the force induced by having the subject hold the arm against gravity.

Previous kinematic studies have reported that the rotator cuff muscles exert gleno-humeral joint compression force during scaption to maintain the humeral head in the glenoid fossa, especially at initial range of scaption against the superior migration force produced by the deltoid muscle. Yanagawa et al. demonstrated that the ISP muscle exerts compression force throughout scaption [30]. The activity value behavior of the middle partition was similar to Yanagawa's outcomes. However, the activity values of the superior and inferior partitions were small during the initial range and peak values were observed at $135^{\circ}$. Hawkes et al. showed that the deltoid muscle induces an inferior shear force at the end range of scaption, and that this force is balanced by the rotator cuff muscles [12]. Thus, the superior and inferior partitions of the ISP may exert this type of balancing force suggested by Hawkes et al. at the end range of scaption.

Several authors reported that the anterior-most region of the humeral insertion of the ISP muscle almost reached 


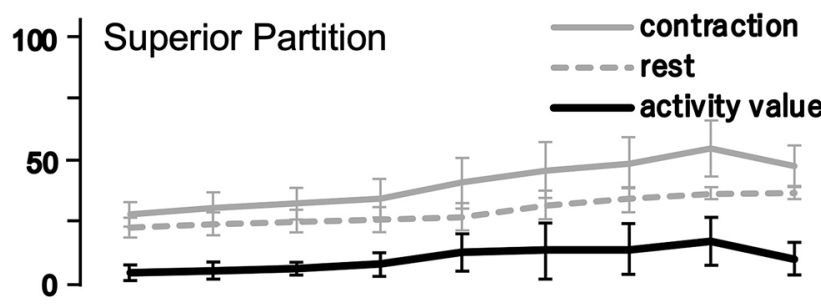

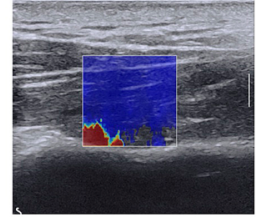

$30 \mathrm{deg}$

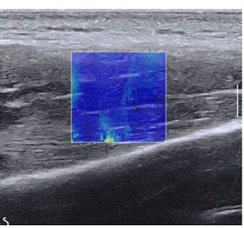

$30 \mathrm{deg}$

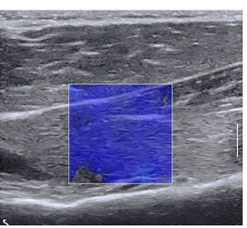

$30 \mathrm{deg}$

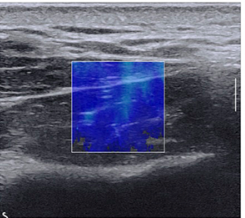

$135 \mathrm{deg}$

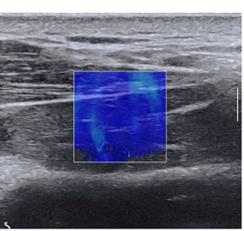

$150 \mathrm{deg}$

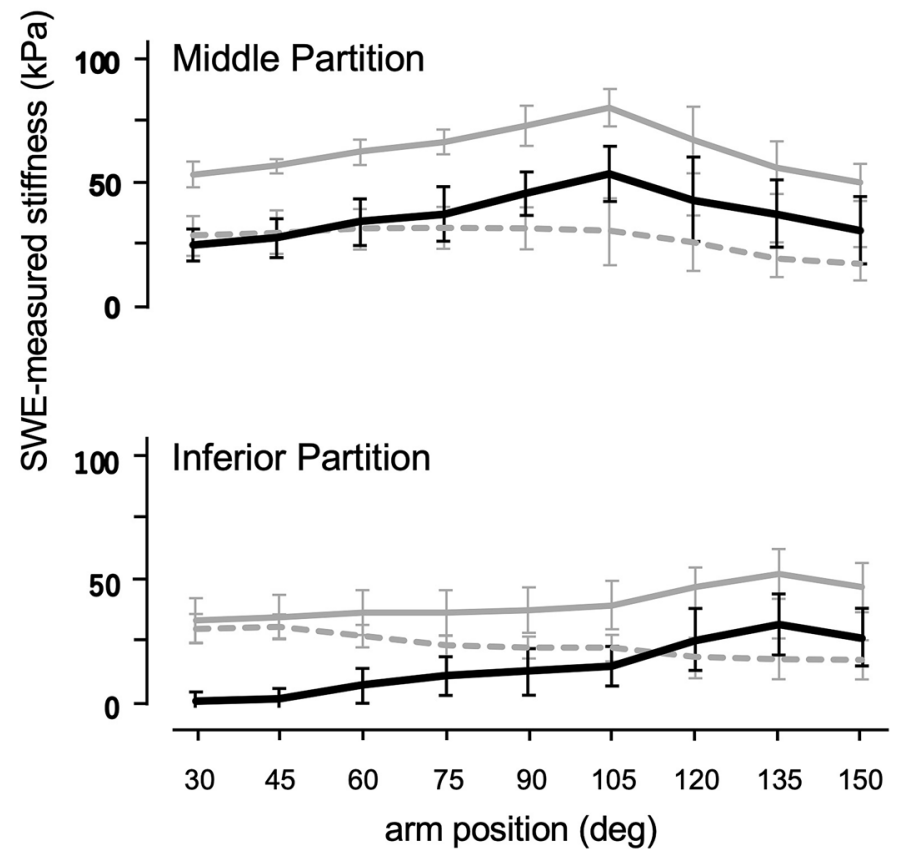

Fig. 3 The shear modulus at rest, at contraction and activity value for each partition during scaption at various shoulder positions. The representative $\mathrm{SWE}$ images were chosen at $30^{\circ}$, peak position $\left(135^{\circ}\right.$ for

the anterior margin of the highest impression of the greater tuberosity [22-25, 31]. Kato et al. demonstrated that the ISP muscle was comprised of two parts, namely the transverse and oblique parts [15]. They found that the transverse part only has a tendinous membrane which is attached to the tendinous portion of the oblique part [15]. Based on these findings, they suggested that the oblique part mainly contributes to shoulder abduction because the tendinous portion of its superior region reaches the anterior-most area of the greater tuberosity, and that the transverse part may provide support and stabilize the tendinous portion of the oblique part during shoulder motion [15]. The difference in the tendinous insertion between the transverse and oblique parts may explain the differences in at-rest values of three partitions, namely, the activity value of the superior partition increased with increasing elevation angle while those of the middle and inferior partitions decreased. Reed et al., using EMG, demonstrated the supraspinatus and ISP muscles had similar initial activation timing during scaption [26], and superior and inferior partitions, $105^{\circ}$ for middle partition), and $150^{\circ}$ from measurements for shear modulus at contraction

Yanagawa et al. showed less muscle force production in the supraspinatus muscle than the ISP muscle at initial range of scaption [30]. These previous results also support the function of middle partition as an initiator of scaption.

Clinically, a rotator cuff tear is one of the most common musculoskeletal disorders. Studies report the tear to include the supraspinatus tendon and/or junction of the supraspinatus and ISP tendons $[13,16]$. Interestingly, some patients with a rotator cuff tear can elevate their arms, even though the supraspinatus tendon is completely torn, while some patients whose tear extended to the ISP tendon can hardly elevate their arm. One possible explanation for this is the compensatory effect imposed by the ISP muscle. If the ISP muscle can exert a joint compression force large enough to suppress the superior migration force produced by the deltoid muscle at the initial range of scaption, the arm could be elevated. Yuri et al. found that the middle partition has a firm capsular attachment area, while the superior and inferior partitions had less or no firm capsular attachment areas 
and bony insertions to the greater tuberosity [31]. Clark et al. suggested that the firm capsular attachment area could contribute to a distribution of the tension to the humeral head [5]. The results of our study indicated that the middle partition might act as the initiator of scaption via the bony insertion of the greater tuberosity and exert enough joint compression force via its capsular attachment.

While EMG and kinematic evaluations have been adopted for assessing muscular function, the former is invasive and has not been successfully implemented in the inferior partition due to wire displacement [1], and the latter has not been applied in the various muscular partitions. In our study, we successfully discriminated the spatio-temporal relationship of the three partitions of the ISP muscle during scaption using SWE. We showed that the middle partition may play a substantial role in initiation of scaption, the inferior partition could act in a dynamic tenodesis manner, and the superior and inferior partitions may oppose the function of the deltoid muscle at the end range of scaption. Additionally, estimates of muscular elongation and shortening can be obtained by quantifying stiffness at rest. These outcomes suggest SWE as a novel technique for precise assessment of the properties of the individual muscular partitions.

There are some limitations in this study. First, the subjects included only young males. Therefore, further studies are needed to extrapolate our findings in clinical setting to an older population presenting different pathologies. Second, the strength at contraction in this study corresponded to the manual muscle test grade 3, namely, subjects held their arms against gravity. While this process could be considered as a weak muscle contraction, it allowed for the evaluation of the independent activations of the ISP muscle partitions. Future studies should evaluate other shoulder positions and loading conditions, as well as their effect on ISP muscle behavior to verify the functional role of different partitions of the ISP muscle.

\section{Conclusion}

Stiffness measured using shear-wave elastography in each partition of the ISP muscle demonstrated different behavior between these partitions during scaption. The middle partition generated force throughout scaption, while the superior and inferior partitions exerted force at end range.

Acknowledgements This study was supported by Grant-in-Aid for JSPS fellows Grant No. 19J10699.

Author contributions KH: data collection, data analysis, and manuscript writing/editing. TY: protocol/project development, data collection, data analysis, and manuscript writing/editing. HG: manuscript writing/editing. YK: protocol/project development, data analysis, and manuscript writing/editing.

\section{Compliance with ethical standards}

Conflict of interest The authors declare that they have no conflict of interest.

Open Access This article is licensed under a Creative Commons Attribution 4.0 International License, which permits use, sharing, adaptation, distribution and reproduction in any medium or format, as long as you give appropriate credit to the original author(s) and the source, provide a link to the Creative Commons licence, and indicate if changes were made. The images or other third party material in this article are included in the article's Creative Commons licence, unless indicated otherwise in a credit line to the material. If material is not included in the article's Creative Commons licence and your intended use is not permitted by statutory regulation or exceeds the permitted use, you will need to obtain permission directly from the copyright holder. To view a copy of this licence, visit http://creativecommons.org/licenses/by/4.0/.

\section{References}

1. Alenabi T, Whittaker R, Kim SY, Dickerson CR (2018) Maximal voluntary isometric contraction tests for normalizing electromyographic data from different regions of supraspinatus and infraspinatus muscles: Identifying reliable combinations. J Electromyogr Kinesiol 41:19-26. https://doi.org/10.1016/j.jelekin.2018.04.007

2. Alenabi T, Whittaker RL, Kim SY, Dickerson CR (2019) Arm posture influences on regional supraspinatus and infraspinatus activation in isometric arm elevation efforts. J Electromyogr Kinesiol 44:108-116. https://doi.org/10.1016/j.jelekin.2018.12.005

3. Bacle G, Gregoire JM, Patat F, Clavert P, de Pinieux G, Laulan J, Lakhal W, Favard L (2017) Anatomy and relations of the infraspinatus and the teres minor muscles: a fresh cadaver dissection study. Surg Radiol Anat 39:119-126. https://doi.org/10.1007/ s00276-016-1707-9

4. Calver R, Alenabi T, Cudlip A, Dickerson CR, Mondal P, Kim SY (2019) Regional activation of supraspinatus and infraspinatus subregions during dynamic tasks performed with free weights. J Electromyogr Kinesiol. https://doi.org/10.1016/j.jelekin.2019.05.009

5. Clark J, Sidles JA, Matsen FA (1990) The relationship of the glenohumeral joint capsule to the rotator cuff. Clin Orthop Relat Res 254:29-34

6. Fabrizio PA, Clemente FR (2014) Anatomical structure and nerve branching pattern of the human infraspinatus muscle. J Bodyw Mov Ther 18:228-232. https://doi.org/10.1016/j.jbmt.2013.11.016

7. Faul F, Erdfelder E, Lang AG, Buchner A (2007) G*Power 3: a flexible statistical power analysis program for the social, behavioral, and biomedical sciences. Behav Res Methods 39:175-191. https://doi.org/10.3758/bf03193146

8. Giambini H, Hatta T, Rezaei A, An KN (2018) Extensibility of the supraspinatus muscle can be predicted by combining shear wave elastography and magnetic resonance imaging-measured quantitative metrics of stiffness and volumetric fat infiltration: a cadaveric study. Clin Biomech (Bristol, Avon) 57:144-149. https ://doi.org/10.1016/j.clinbiomech.2018.07.001

9. Gray H, Williams PL, Warwick R (1980) Gray's anatomy, 36th edn. Saunders, Churchill Livingstone, Philadelphia Edinburgh; New York

10. Hatta T, Giambini H, Itoigawa Y, Hooke AW, Sperling JW, Steinmann SP, Itoi E, An KN (2017) Quantifying extensibility of rotator cuff muscle with tendon rupture using shear wave elastography: a cadaveric study. J Biomech 61:131-136. https://doi. org/10.1016/j.jbiomech.2017.07.009 
11. Hatta T, Giambini H, Uehara K, Okamoto S, Chen S, Sperling JW, Itoi E, An KN (2015) Quantitative assessment of rotator cuff muscle elasticity: reliability and feasibility of shear wave elastography. J Biomech 48:3853-3858. https://doi.org/10.1016/j.jbiom ech.2015.09.038

12. Hawkes DH, Khaiyat OA, Howard AJ, Kemp GJ, Frostick SP (2019) Patterns of muscle coordination during dynamic glenohumeral joint elevation: an EMG study. PLoS ONE 14:e0211800. https://doi.org/10.1371/journal.pone.0211800

13. Jeong JY, Min SK, Park KM, Park YB, Han KJ, Yoo JC (2018) Location of rotator cuff tear initiation: a magnetic resonance imaging study of 191 shoulders. Am J Sports Med 46:649-655. https ://doi.org/10.1177/0363546517748925

14. Joseph R, Alenabi T, Lulic T, Dickerson CR (2019) Activation of supraspinatus and infraspinatus partitions and periscapular musculature during rehabilitative elastic resistance exercises. Am J Phys Med Rehabil 98:407-415. https://doi.org/10.1097/ PHM.0000000000001116

15. Kato A, Nimura A, Yamaguchi K, Mochizuki T, Sugaya H, Akita K (2012) An anatomical study of the transverse part of the infraspinatus muscle that is closely related with the supraspinatus muscle. Surg Radiol Anat 34:257-265. https://doi.org/10.1007/ s00276-011-0872-0

16. Kim HM, Dahiya N, Teefey SA, Middleton WD, Stobbs G, StegerMay K, Yamaguchi K, Keener JD (2010) Location and initiation of degenerative rotator cuff tears: an analysis of three hundred and sixty shoulders. J Bone Joint Surg Am 92:1088-1096. https://doi. org/10.2106/JBJS.I.00686

17. Koo TK, Guo JY, Cohen JH, Parker KJ (2013) Relationship between shear elastic modulus and passive muscle force: an exvivo study. J Biomech 46:2053-2059. https://doi.org/10.1016/j. jbiomech.2013.05.016

18. Koo TK, Li MY (2016) A guideline of selecting and reporting intraclass correlation coefficients for reliability research. J Chiropr Med 15:155-163. https://doi.org/10.1016/j.jcm.2016.02.012

19. Kronberg M, Nemeth G, Brostrom LA (1990) Muscle activity and coordination in the normal shoulder. An electromyographic study. Clin Orthop Relat Res 257:76-85

20. Kuwahara Y, Yuri T, Fujii H, Kiyoshige Y (2017) Functions of the subregions of the infraspinatus during lateral rotation. Surg Radiol Anat 39:1331-1336. https://doi.org/10.1007/s00276-017-1886-z

21. McMahon PJ, Jobe FW, Pink MM, Brault JR, Perry J (1996) Comparative electromyographic analysis of shoulder muscles during planar motions: anterior glenohumeral instability versus normal. J Shoulder Elbow Surg 5:118-123. https://doi.org/10.1016/s1058 -2746(96)80006-1

22. Mochizuki T, Sugaya H, Uomizu M, Maeda K, Matsuki K, Sekiya I, Muneta T, Akita K (2008) Humeral insertion of the supraspinatus and infraspinatus. New anatomical findings regarding the footprint of the rotator cuff. J Bone Jt Surg Am 90:962-969. https ://doi.org/10.2106/JBJS.G.00427
23. Momma D, Nimura A, Muro S, Fujishiro H, Miyamoto T, Funakoshi T, Mochizuki T, Iwasaki N, Akita K (2018) Anatomic analysis of the whole articular capsule of the shoulder joint, with reference to the capsular attachment and thickness. J Exp Orthop 5:16. https ://doi.org/10.1186/s40634-018-0134-8

24. Nimura A, Kato A, Yamaguchi K, Mochizuki T, Okawa A, Sugaya H, Akita K (2012) The superior capsule of the shoulder joint complements the insertion of the rotator cuff. J Shoulder Elbow Surg 21:867-872. https://doi.org/10.1016/j.jse.2011.04.034

25. Nozaki T, Nimura A, Fujishiro H, Mochizuki T, Yamaguchi K, Kato R, Sugaya H, Akita K (2015) The anatomic relationship between the morphology of the greater tubercle of the humerus and the insertion of the infraspinatus tendon. J Shoulder Elbow Surg 24:555-560. https://doi.org/10.1016/j.jse.2014.09.038

26. Reed D, Cathers I, Halaki M, Ginn K (2013) Does supraspinatus initiate shoulder abduction? J Electromyogr Kinesiol 23:425-429. https://doi.org/10.1016/j.jelekin.2012.11.008

27. Sasaki K, Toyama S, Ishii N (2014) Length-force characteristics of in vivo human muscle reflected by supersonic shear imaging. J Appl Physiol 117:153-162. https://doi.org/10.1152/japplphysi ol.01058.2013

28. Sharkey NA, Marder RA, Hanson PB (1994) The entire rotator cuff contributes to elevation of the arm. J Orthop Res 12:699-708. https://doi.org/10.1002/jor.1100120513

29. Sigrist RMS, Liau J, Kaffas AE, Chammas MC, Willmann JK (2017) Ultrasound elastography: review of techniques and clinical applications. Theranostics 7:1303-1329. https://doi.org/10.7150/ thno. 18650

30. Yanagawa T, Goodwin CJ, Shelburne KB, Giphart JE, Torry MR, Pandy MG (2008) Contributions of the individual muscles of the shoulder to glenohumeral joint stability during abduction. J Biomech Eng 130:021024. https://doi.org/10.1115/1.2903422

31. Yuri T, Kobayashi H, Takano Y, Yoshida S, Naito A, Fujii H, Kiyoshige Y (2019) Capsular attachment of the subregions of rotator cuff muscles. Surg Radiol Anat 41(11):1351-1359. https ://doi.org/10.1007/s00276-019-02288-7

32. Yuri T, Kuwahara Y, Fujii H, Kiyoshige Y (2017) Functions of the subregions of the supraspinatus muscle. Clin Anat 30:347-351. https://doi.org/10.1002/ca.22843

33. Yuri T, Mura N, Yuki I, Fujii H, Kiyoshige Y (2018) Contractile property measurement of the torn supraspinatus muscle using real-time tissue elastography. J Shoulder Elbow Surg 27:17001704. https://doi.org/10.1016/j.jse.2018.02.065

Publisher's Note Springer Nature remains neutral with regard to jurisdictional claims in published maps and institutional affiliations. 